\title{
Profitability of Summer BARI Hybrid Tomato Cultivation in Jessore District of Bangladesh
}

\author{
M. R. KARIM ${ }^{1 *}$, M. S. RAHMAN ${ }^{2}$ \& M. S. ALAM ${ }^{3}$ \\ ${ }^{1}$ Agril. Economics and Statistics Section, Horticulture Research Centre, Bangladesh Agricultural \\ Research Institute, Gazipur, Bangladesh \\ ${ }^{2}$ Agricultural Economics Division, Bangladesh Agricultural Research Institute, Gazipur, Bangladesh \\ ${ }^{3}$ Horticulture Research Centre, Bangladesh Agricultural Research Institute, Gazipur, Bangladesh
}

\begin{abstract}
The present study was conducted at Bagherpara thana under Jessore district to assess the profitability, contribution of factors to production and changes in socio-economic status of the farmers. About $42 \%$ and $21 \%$ of total variable cost was incurred for tunnel preparation and using human labour, respectively. The average yield of BARI hybrid tomato was found $32.78 \mathrm{t} / \mathrm{ha}$. The average return per hectare over variable cost is observed to be Tk 11,44,387 on full cost basis and Tk 12,07,481 on cash cost basis. On an average benefit cost ratio was found to be 4.19 on full cost basis and 5.09 on cash cost basis. The cost per kilogram of hybrid tomato cultivation was Tk 10.94 and return from one kilogram of tomato production was Tk 45.83. The functional analysis shows that MP and TSP had positive significant contribution to yield while human labour, hormone, irrigation and seed had negative significant impact on yield of hybrid tomato. The overall socio-economic status of the sample farmers was found increased by 20.33 percent. High price of tunnel materials, timely non availability of hormone, insect and diseases attack were reportedly the major problems for tomato production.
\end{abstract}

Key words: Hybrid tomato, profitability, socio-economic status.

\section{INTRODUCTION}

Bangladesh is an agro-based country where agriculture is considered as backbone of her economy. About 80 percent of its population lives in rural areas and 62 percent of total labor force are engaged in agriculture (BBS, 2005). Agriculture plays a vital role through employment generation, poverty alleviation, food security, enhance standard of living by increasing income level of rural population.

Many developing countries like Bangladesh benefited from the green revolution in cereal production in the past but were not able to substantially reduce poverty and malnutrition. Vegetable production can help farmers to generate income which eventually alleviate poverty. Among the vegetables tomato is one of the most important vegetables in terms of acreage, production, yield, commercial use and consumption. At present $6.10 \%$ (BBS, 2005) area is under tomato cultivation both in winter and summer. It is the most consumable vegetable crop after potato and sweet potato occupying the top of the list of canned vegetable (Chowdhury, 1979). It is cultivated all over the

* Corresponding author: Principal Scientific Officer, Agril. Economics and Statistics Section, HRC, BARI, Gazipur, Bangladesh

(C) 2009 School of Agriculture and Rural Development, Bangladesh Open University, All rights reserved. 
country due to its adaptability to wide range of soil and climate (Ahmed, 1976). However, the yield of the crop is very low compared to those obtained in some advanced country ( Sharfuddin and Siddique, 1985). In Bangladesh congenial atmosphere remains for tomato production during low temperature winter season that is early November is the best time for tomato planting in our country (Hossain et al., 1986). It is a good source of vitamin C (31 mg per 100g), vitamin A, calcium, iron etc. (Matin et al., 1996). Although tomato plants can grow under a wide range of climatic conditions, they are extremely sensitive to hot and wet growing conditions, the weather which prevails in the summer to rainy season in Bangladesh. But limited efforts have been given so far to overcome the high temperature barrier preventing fruit set in summer-rainy (hot-humid) season. Its demand for both domestic and foreign markets has increased manifold due to its excellent nutritional and processing qualities (Hossain et. al, 1999). Considering the growing demand and importance of tomato, Bangladesh Agricultural Research Institute (BARI) has taken initiative to develop off-season summer and rainy season tomatoes. So far BARI has developed and released 2 hybrid tomato varieties i.e. BARI hybrid tomato- 3 and 4 which can be grown during summer and rainy season under polytunnel. But very little information has been generated about the profitability and adoption of hybrid tomato cultivation technologies by the farmers in the country. Generalization from studies conducted by home and abroad (Mohiuddin et al., 2007; Zaman et al., 2006; Islam, 2005; Rahman et al., 1998; Ali and Gupta, 1978; Gupta and Rao, 1978) regarding the tomato production may not be always applicable due to considerable variation in attributes of the technologies and for various others factors. Fortunately, the farmers of Bagherpara thana under Jessore district started to adopt this technology as a pioneer farmer since 2005. It is recognized that in order to expand the area of this crop as well as to fit this crop in the farmers cropping system, studies are needed to ascertain its cost and return situation in relation to profitability, input use and farmer's resource use efficiency. Keeping all these factors in consideration the present study was undertaken to provide information through fulfillment of the following objectives.

\section{OBjectives}

1. To ascertain the cost and return of hybrid tomato cultivation;

2. To study interrelationship between inputs and outputs of hybrid tomato cultivation;

3. To assess the changes in socio economic status of the growers due to hybrid tomato cultivation.

\section{METHODOLOGY}

The present study was conducted at Bagherpara thana of Jessore district. The study area was purposively selected considering the higher concentration of BARI hybrid tomato-3 and 4 cultivation during summer season. The study was carried out by using formal survey method. At first a complete list of the tomato growers was prepared and a total of 42 farmers were chosen randomly from the list to collect the information regarding tomato cultivation. The sample farmers were classified as small and medium classes on the basis of their total land holdings. Large category of farm was not considered because of non availability of large farmers in the list. Data were collected through pre-designed interview schedule during the period of summer 2007. The unit of data collection was a single hybrid tomato plot of each selected farmers where detailed information regarding this crop cultivation were taken and analysis was done on per hectare basis. Although some of the selected farmers continued to harvest the crop upto December but yield data and other information were taken upto last week of October considering summer period. Conventional statistical analysis using average, percentages, ratio etc. were applied to derive meaningful findings in this study. Perceived Impact Score (PIS) technique (Rahman, 2006) was used to elicit the impact of hybrid tomato cultivation on the socio-economic status of the farmers. Each farmer indicated the extent of change that has been occurred for tomato cultivation by checking any one of the four responses, i.e. excellent, moderate, average and no change. The weights assigned were 3, 2, 1 and 0 for excellent, moderate, average and no change respectively. The PIS for a particular change item was standardized by using the following formula: 


$$
\text { Standardized PIS (SPIS) }=\frac{\text { Observed perceived impact score }}{\text { Possible perceived impact score }} \times 100
$$

A production function analysis was carried out to explore the contribution and productivity of individual inputs. Cobb-Douglas production model was used because of the best fit of the sample data. The functional form of the Cobb-Douglas multiple regression equation was as follows:

$$
Y=a X_{1}{ }^{b 1} X_{2}{ }^{b 2}-----X_{6}{ }^{b 6}+U_{i}
$$

For the purpose of the present empirical exercise the Cobb-Douglas production function was converted into the following logarithmic (Double log) form with variables specific as under:

$$
\begin{aligned}
& L_{n} Y=\operatorname{Ln} a+b_{i} \operatorname{Ln} X_{1}+b_{2} \operatorname{Ln} X_{2}+b_{3} \operatorname{Ln} X_{3}+b 4 \operatorname{Ln} X_{4}+b_{5} \operatorname{Ln} X_{5}+b_{6} \operatorname{Ln} X_{6}+U i \\
& \text { Where, } \quad Y=\quad \text { Gross return (Tk/ha) } \\
& \mathrm{X}_{1}=\quad \text { Human Labour (Tk/ha) } \\
& \mathrm{X}_{2}=\quad \text { Cost of TSP (Tk/ha) } \\
& \mathrm{X}_{3}=\quad \text { Cost of MP (Tk/ha) } \\
& \mathrm{X}_{4}=\quad \text { Cost of Hormone }(\mathrm{Tk} / \mathrm{ha}) \\
& X_{5}=\quad \text { Irrigation cost }(T k / h a) \\
& X_{6}=\quad \text { Cost of Seed }(\mathrm{Tk} / \mathrm{ha}) \\
& \mathrm{a}=\quad \text { Constant of intercept } \\
& b_{i}, b_{2} \text {---------- } b_{6}=\quad \text { Coefficient of the respective variable } \\
& \mathrm{U} i=\quad \text { Error term. }
\end{aligned}
$$

\section{Results AND Discussion}

\section{Cost of hybrid tomato cultivation}

In this study cost of production was calculated on the basis of variable inputs like seed, fertilizer, manure, human labour, hormone, pesticide, irrigation etc. A perusal of Table 1 revealed that total variable cost of hybrid tomato cultivation was Tk 3,58,577 per hectare. When only cash costs was considered the cost per hectare was Tk 2,95,182 which is about 82 percent of the total cost. Among the different cost items tunnel preparation cost was the major cost items which accounted for about $42 \%$ of the total cost. The second highest $(20.57 \%)$ cost item was human labour followed by insecticide (12.70\%). There is no wide variation among different categories of farms in the cost of tomato cultivation. However, higher manure cost implies higher use of manure by small farmers over medium farmers. On the contrary, medium farmers appear to use more fertilizer and irrigation water.

\section{Table 1. Structure of cost of hybrid tomato cultivation}

\begin{tabular}{lcccc}
\hline \multicolumn{1}{c}{ Cost items } & Small & Medium & All & Percentage \\
\hline Human labour: & & & & \\
$\quad$ Family & 64641 & 62149 & 63395 & 17.68 \\
$\quad$ Hired & 8461 & 12290 & 10375 & 2.89 \\
$\quad$ Total & 73101 & 74439 & 73770 & 20.57 \\
Land preparation cost & 6526 & 6662 & 6594 & 1.84 \\
Seed cost & 8188 & 8114 & 8151 & 2.27 \\
Fertilizer & 26795 & 28175 & 27485 & 7.66 \\
Manure & 4362 & 2361 & 3362 & 0.94 \\
Tunnel cost & 146380 & 155941 & 151160 & 42.16 \\
Irrigation cost & 6476 & 6827 & 6652 & 1.86 \\
Hormone & 35504 & 36037 & 35771 & 9.98 \\
Insecticide cost & 45003 & 46263 & 45633 & 12.73 \\
Total variable cost: & & & & 100.00 \\
$\quad$ Full cost basis & 352335 & 364820 & 358577 & \\
Cash cost basis & 287694 & 302671 & 295182 & \\
\hline
\end{tabular}

Source: Field survey, 2008 


\section{Profitability of hybrid tomato cultivation}

Return was calculated by multiplying yield with its price. Return per hectare of tomato cultivation is shown in Table 2. The average yield of summer tomato was $32.78 \mathrm{t} / \mathrm{ha}$ which was found a bit higher for the medium farmers. The average gross return was calculated as Tk 15,02,664 per hectare. The average price of hybrid tomato upto last week of October was Tk 45.83 per kilogram. The average return over variable cost was observed to be Tk 11,44,387 on full cost basis and Tk $12,07,481$ on cash cost basis. The return over variable cost was found higher for the medium farmers compared to small farmers. On the average, benefit cost ratio was found to be 4.19 on full cost basis and 5.09 on cash cost basis.

Table 2. Return from hybrid tomato cultivation (Tk. /hec.)

\begin{tabular}{lccc}
\hline \multicolumn{1}{c}{ Particulars } & Small & Medium & All \\
\hline Yield (t/ha) & 32.45 & 33.12 & 32.78 \\
Gross return & 1487645 & 1517682 & 1502664 \\
Total variable cost & & & \\
$\quad$ Full cost basis & 352335 & 364820 & 358577 \\
$\quad$ Cash cost basis & 287694 & 302671 & 295182 \\
Return over variable cost & 1135311 & 1152862 & 1144087 \\
$\quad$ Full cost basis & 1199951 & 1215011 & 1207481 \\
$\quad$ Cash cost basis & & & \\
Benefit cost ratio & 4.22 & 4.16 & 4.19 \\
$\quad$ Full cost basis & 5.17 & 5.01 & 5.09 \\
$\quad$ Cash cost basis & 10.86 & 11.01 & 10.94 \\
Cost per kilogram & 45.84 & 45.82 & 45.83 \\
Return per kilogram & & & \\
\hline
\end{tabular}

Source: Field survey, 2008

\section{Contribution of different inputs to hybrid tomato production}

For producing hybrid tomato different types of variable inputs were employed. Initially 10 variables were included but to improve the result, some of the independent variables were omitted to allow the selection of the best set of explanatory variables. Estimated values of coefficients and related statistics of Cobb-Douglas production function are presented in Table 3. The coefficient of determination $\left(\mathrm{R}^{2}\right)$ tells how well the sample regression line fits the data (Gujarati, 1995). The coefficient of determination $\left(R^{2}\right)$ was 0.59 , which indicates that around 59 percent of the variations in gross return were explained by the independent variables included in the model. The F-value of the equation is significant at $1 \%$ level implying that the variation in return from summer tomato production mainly depends upon the independent variables included in the model.

Table 3. Estimated values of coefficients and related statistics of Cobb-Douglas production function

\begin{tabular}{|c|c|c|}
\hline Variables & Co-efficient & t-value \\
\hline Intercept & $45.31^{\star \star \star}$ & 2.89 \\
\hline Human labour $\left(\mathrm{X}_{1}\right)$ & $-0.23^{* *}$ & -2.10 \\
\hline $\operatorname{TSP}\left(X_{2}\right)$ & $0.53^{*}$ & 1.79 \\
\hline $\operatorname{MP}\left(X_{3}\right)$ & $0.17^{\text {** }}$ & 2.32 \\
\hline Hormone $\left(\mathrm{X}_{4}\right)$ & $-1.12^{*}$ & -1.84 \\
\hline Irrigation $\left(X_{5}\right)$ & -0.009 & 0.48 \\
\hline Seed $\left(X_{6}\right)$ & $-0.94^{\star *}$ & -2.01 \\
\hline $\mathrm{R}^{2}$ & & \\
\hline F-value & & \\
\hline
\end{tabular}

Note: ${ }^{*}, *$ and ${ }^{* \star \star}$ indicate significant at $10 \%, 5 \%$ and $1 \%$ level 


\section{Input-output relationship}

The negative and significant regression coefficient of human labour $\left(X_{1}\right)$ and seed $\left(X_{6}\right)$ indicated the inefficient use of these input. It implies that $1 \%$ increase in human labour and seed cost, keeping other factors constant, would decrease the gross return by 0.23 and 0.94 percent respectively. The regression coefficient of hormone $\left(\mathrm{X}_{4}\right)$ was also negative and significant at $10 \%$ level. The regression coefficient of MP $\left(X_{3}\right)$ was positive and significant at $5 \%$ level while the regression coefficient of TSP $\left(\mathrm{X}_{2}\right)$ was positive and significant at $10 \%$ level. The positive coefficient of MP and TSP imply that $1 \%$ increase in the cost of these inputs keeping other factors constant would increase the gross returns by 0.17 and 0.53 percent respectively. The coefficient of irrigation $\left(\mathrm{X}_{5}\right)$ was found negative and insignificant.

\section{Changes in socio-economic status of the farmers}

Percentage distribution of the respondent according to their perception on different change items has been shown in Table 4. It is observed that the highest 7 percent excellent change has been occurred on income for growing hybrid tomato based on the perception of the respondents. The change occured 3 to $7 \%$ for excellent change, 9 to $24 \%$ for moderate change, 21 to $52 \%$ for average change and 19 to $70 \%$ for no change. From percentage distribution, it is clear that BARI hybrid tomato-3 and 4 cultivation has brought changes in socio-economic status of the sample farmers.

Table 4. Socio-economic changes of the farmers

\begin{tabular}{lccccc}
\hline \multirow{2}{*}{ Items } & \multicolumn{4}{c}{ Nature of changes (\%) } & \multirow{2}{*}{ Total } \\
\cline { 2 - 5 } & Excellent & Moderate & Average & No & \\
\hline Food and nutrition & 5 & 19 & 40 & 36 & 100 \\
Housing condition & - & 09 & 21 & 70 & 100 \\
Using sanitary latrine & - & 11 & 31 & 58 & 100 \\
Clothing & 5 & 15 & 38 & 43 & 100 \\
Household furniture & - & 12 & 23 & 65 & 100 \\
Knowledge about summer tomato production & 3 & 21 & 52 & 24 & 100 \\
Income & 7 & 24 & 50 & 19 & \\
\hline
\end{tabular}

Source: Field survey, 2008

\section{Changes in socio-economic status on the basis of PIS}

The impact has been measured on the basis of farmer's perception about the extent of change that has been occurred due to tomato cultivation. Perceived impact score (PIS) was computed for each change item by summing the weights for responses of the respondents against that change item. PIS of a selected change item indicates how much change occurs due to hybrid tomato cultivation during summer season. The higher the PIS of a change item, the more is the impact of tomato cultivation. The possible PIS of any change item ranged from a minimum of zero to a maximum of $126(42 \times 3)$. The overall SPIS of 7 change items was found to be 20.33 percent which reflects that the overall change in socio-economic status of the farmers increased by 20.33 percent for cultivating hybrid tomato (Table 5).

Table 5. Impact of perceived items on the basis of PIS

\begin{tabular}{lcccc}
\hline \multicolumn{1}{c}{ Impact } & PIS & Standardized & \% & Rank order \\
\hline Food and nutrition & 39 & 30.95 & 17.26 & 3 \\
Housing condition & 17 & 13.49 & 7.52 & 7 \\
Using sanitary latrine & 23 & 18.25 & 10.18 & 5 \\
Clothing & 34 & 26.98 & 15.04 & 4 \\
Household furniture & 20 & 15.87 & 8.85 & 6 \\
Knowledge about summer tomato production & 43 & 34.13 & 19.03 & 2 \\
Income & 50 & 39.68 & 22.12 & 1 \\
\hline Overall change & \multicolumn{3}{c}{20.33} \\
\hline
\end{tabular}

Source: Field survey, 2008 
For calculating the impact of hybrid tomato cultivation, 7 selected change items have been arranged in rank order according to their SPIS values. Data contained in Table 5 indicates that the 7 change items were not equally important in terms of extent of change occurred. The highest SPIS was found $39.68(22.12 \%)$ on income while the lowest was $13.49(7.52 \%)$ for housing condition. So the impact on income was found to be the most important item among the selected items.

\section{Constraints of hybrid tomato cultivation}

Although hybrid tomato cultivation was observed to be a profitable crop, there were several constraints to its higher production. Constraints were identified based on the questions asked to the respondents and then they were edited and summarized to arrive at only few problems. It is observed from Table 6 that about one half of the farmers reported high price of tunnel materials was the problem. Timely non-availability of hormone and insect and diseases attack were the problems reported by each 40 per cent of the respondents. Timely non-availability of seed as a problem mentioned by 36 per cent of respondent in the study area.

\section{Table 6. Constraints to hybrid tomato cultivation}

\begin{tabular}{lccc}
\hline \multicolumn{1}{c}{ Items } & \multicolumn{3}{c}{ Percent of response } \\
\cline { 2 - 4 } & Small & Medium & All farms \\
\hline 1. Timely non-availability of seed & 38 & 31 & 36 \\
2. Attack of insect \& diseases & 41 & 38 & 40 \\
3. High price of fertilizer & 10 & 8 & 10 \\
4. High price of insecticide & 17 & 15 & 17 \\
5. Timely non-availability of hormone & 41 & 38 & 40 \\
6. High price of tunnel materials & 48 & 46 & 48 \\
\hline
\end{tabular}

Source: Field survey, 2008

\section{CONCLUSION}

BARI hybrid tomato- 3 and 4 is a profitable crop on the basis of its return to investment. Farmers are highly pleased and encouraged with these technologies as they have the bright scope to increase their income by cultivating this crop. For upgrading the knowledge of the farmers, it is necessary to disseminate the latest information of the improved technological package of tomato cultivation which will enhance the farmers to increase production. From the analysis it is clear that BARI hybrid tomato-3 and 4 cultivation has brought changes in socio-economic status of the sample farmers. The overall socio economic status of the farmers increased by about 20 percent. As this crop is very labour intensive crop, there is an ample scope for increasing employment in the rural areas of Bangladesh.

\section{Literature Cited}

Ahmed, K. U. 1976. "Phul Phal O Shak Shabji (in Bangla)". 2nd Edition, Alhaj Kamaluddin Ahmed, Banglow No. 2, Farm Gate, Dhaka, Bangladesh. p.470.

Ali, S. M. and Gupta, B. K. 1978. Effect of N, P and K Fertilization on Tomato. Horticulture Abstract, 48(12), 92.

BBS, 2005. Yearbook of Agricultural Statistics of Bangladesh. Planning Division, Ministry of Planning, Govt. of the People's Republic of Bangladesh, Dhaka.

Chowdhury, B. 1979. Vegetables. 6th Edition, The Director, National Book Trust, New Delhi, India. p.46.

Gupta, A. and Rao, G.G. 1978. Note on Response of Spring Planted Tomato to Irrigation and Nitrogen. Indian Journal Agric. Sci. 48, 183-184.

Gujarati, D.N. 1995. Basic Econometrics. Third Edition, New York, McGraw Hill Kogakusha Ltd. 
Hossain, M. A., Goffer, M. A., Chowdhury, J. C. S., Rahman, M. S. and Hossain, M. I. 1999. A Study on Postharvest Practices and Loss of Tomato in Some Selected Areas of Bangladesh. Bangladesh J. Agril. Res. 24(2), 299.

Hossain, M. M., Karim, M. K., Haque, M. M. and Hassain, A. K. M. A. 1986. Performance of Some Promising Tomato Lines Planted at Different Dates. Annual Report, Vegetable Section, Division of Horticulture, Bangladesh Agricultural Research Institute, Gazipur. pp. 9-12.

Islam, M. N. 2005. Economic Analysis of Some Selected Crops Under Different Treatment in Saline Soil at Charmajid, Noakhali. Annual Research Report, Agril. Economics Division, BARI, Gazipur.

Matin, M. A., Huq, A. S. M. A., Karim, M. R. and Baksha, E. 1996. Farm Level Yield Analysis of Tomato Cultivation in Selected Areas of Bangladesh: An Economic Profile. Bangladesh J. Agril. Res. 21(1), 50-57.

Mohiuddin, M., Uddin, M. S., Rashid, M. H., Hossain, K. M. F. and Matin, M. A. 2007. Adoption and Profitability of Improved Tomato Variety in the Chittagong Region of Bangladesh. Journal of Soil and Nature, 1(3). pp. 52-58.

Rahman, M. A., Haider, J., Shaha, U. K., Chowdhury, A. R. and Chowdhury, M. M. U. 1998. Economically Viable Rates of Fertilizers and Manure for Maximizing Growth and Yield of Year Round Tomato. Bangladesh J. Agril. Res., 23(3), 551-559.

Rahman, M. S. 2006. Impact of RDRS Poultry Credit (Layer) on Rural Woman in Some Selected Areas of Nilphamari District. Unpublished [M S Thesis], Dept. of Agricultural Finance, Bangladesh Agricultural Universuty, Mymensingh.

Sharfudin, A. F. M. and Siddique, M. A. 1985. Sabji Bigyan. 1st Edition, Bangladesh Agricultural University, Mymensingh. p.4.

Zaman, M. M., Anawarul Huq A S. M. and. Chowdhury, M. J.A. 2006. Production Potentiality of Summer Tomato in Jamalpur Region. Int. J. Sustain. Crop Production, 1(2), 12-15. 